DOI: 10.12731/wsd-2017-1-41-55

УДК 616.4

\title{
ЭПИДЕМИОЛОГИЧЕСКИЕ \\ И КЛИНИКО-ЛАБОРАТОРНЫЕ ОСОБЕННОСТИ РАЗЛИЧНЫХ ВАРИАНТОВ ЛИМФОМ В РЕСПУБЛИКЕ ХАКАСИЯ ПО РЕЗУЛЬТАТАМ ИЗУЧЕНИЯ ПЕРВИЧНОЙ ЗАБОЛЕВАЕМОСТИ В 2014 Г.
}

Смирнова О.В., Штыгашева О.В., Каблуков В.С.

Цель. Цель исследования - изучение эпидемиологических особенностей первичной заболеваемости лимфомами и основных диагностических показателей (наличие B-симптомов, стадия Ann-Arbor, cтатус по ECOG, лабораторные признаки, характерные зоны поражения, наличие экстранодальных очагов) при различных клинико-морфологических вариантах лимфом в Республике Хакасия по материалам ГБУЗ РХ «Клинического онкологического диспансера» за 2014 г.

Метод или методология проведения работы. Исследование проведено методом ретроспективного анализа.

Результаты. Выявлены следующие эпидемиологические особенности: чаще встречаются неходжкинские лимфомы (НХЛ); заболеваемость лии мужского пола выше, чем женского; среди уточненных морфологических вариантов ЛГМ распространен нодулярный склероз и лимфоидное преобладание, среди НХЛ имеет наибольшее распространение диффузная неходжкинская лимфома; отмечено, что НХЛ чаще встречается у городского население. Установлены достоверно значимые различия по следующиим показателям: возрастной критерий - для ЛГМ характерен возраст $<60$ лет, для НХЛ >60 лет; характерные зоны поражения - при ЛГМ чаще поражаются следующие группь лимфатических узлов: подмышечные, ворот печени, паракавальные, чревные (верхне-абдоминальные), паравертебральные (нижне-абдоминальные), и подвздошные.

Область применения результатов. Организация здравоохранения, онкология, внутренние болезни.

Ключевые слова: ходжкинские лимфомы; неходжкинские лимфомы; распространенность; морфологические варианты; стадирование; характерные зоны поражения. 


\title{
EPIDEMIOLOGICAL \\ AND CLINICAL-LABORATORY FEATURES \\ OF THE VARIOUS VARIANTS OF LYMPHOMAS \\ IN THE REPUBLIC OF KHAKASSIA ON THE RESULTS OF THE STUDY THE PRIMARY DISEASE IN 2014
}

\author{
Smirnova O.V., Shtygasheva O.V., Kablukov V.S.
}

Purpose. The purpose of this study epidemiological features of primary incidence of lymphomas and the main diagnostic indicators (presence of b-symptoms, stage of Ann-Arbor, status in ECOG, laboratory signs, typical lesions, the presence of extranodal lesions) in different morphological variants of lymphomas in the Republic of Khakassia according to the materials of "Clinical oncologic dispensary» in 2014.

Methodology. The research was conducted by retrospective analysis.

Results. Revealed the following epidemiological characteristics: the more common non-Hodgkin's lymphoma (NHL); the incidence in males is higher than women's; among refined morphological variants LGM disseminated nodular sclerosis and lymphoid predominance among NHL has the greatest distribution of diffuse non-Hodgkin's lymphoma; noted that NHL is more common in the urban population. Reliably established significant differences according to the following criteria: age criterion for LGM characteristic age $<60$ years for the NHL $>60$ years; characteristic zone at the LGM often affects the following groups of lymph nodes: axillary, porta hepatic, parkovanie, celiac (upper-abdominal), paravertebral (lower-abdominal), iliac.

Practical implications. Health Organization, oncology, internal medicine.

Keywords: Hodgkin's lymphoma; non-Hodgkin's lymphoma; prevalence; morphological variants; staging; the characteristic of the affected area.

\section{Введение}

Лимфома - это любое новообразование лимфоидной или ретикулоэндотелиальной ткани, которое представляет собой солидную опухоль, состоящую из примитивных клеток, напоминающих лимфоциты, плазматические клетки и гистиоциты [1, с. 1128]. Своевременная и точная диагностика лимфом является сложным и наукоемким процессом. Это связано с многообразием клинических форм, цитологическим сходством нормальных и опухолевых лимфоцитов, близостью гистологических про- 
явлений разных вариантов лимфом, неоднозначным или аберрантным иммунофенотипом [2, с. 266]. Появление инновационных препаратов, эффективных в лечении определенных видов лимфом, существенно повышает требования к точности диагностики. По данным многочисленных международных эпидемиологических исследований в разных странах у представителей разных этнических групп отмечается неоднородное распространение лимфом, наблюдаются социально-экономические и территориальные различия в заболеваемости $[3$, с. $136 ; 4$, с. $11 ; 5$, с. $630 ; 6$, с. $477 ; 7$, с. $59 ; 8$, с. $113 ; 9$, с. 139]. В связи с этим важной становится задача изучения эпидемиологических особенностей и диагностических показателей при различных клинико-морфологических вариантах лимфом, во взаимосвязи с этническим компонентом.

\section{Цель исследования}

Изучение эпидемиологических особенностей первичной заболеваемости лимфомами и основных диагностических показателей (наличие B-симптомов, стадия Ann - Arbor, статус по ECOG, лабораторные признаки, характерные зоны поражения, наличие экстранодальных очагов) при различных клинико-морфологических вариантах лимфом в Республике Хакасия по материалам ГБУЗ РХ «Клинического онкологического диспансера» за 2014 г.

\section{Материалы и методы исследования}

Исследование проведено на базе ГБУЗ РХ «Республиканского клинического онкологического диспансера», путем ретроспективного анализа. Объектом исследований служили данные 68 архивных историй болезней 19 пациентов в возрасте от 11 до 79 лет, проходивших стационарное лечение в ГБУЗ РХ «Республиканском клиническом онкологическом диспансере» с диагнозом: «Новообразования лимфатической и кроветворной ткани» $(\mathrm{C} 81-85,96)$ за 2014 г. Вариант лимфомы устанавливался в соответствии с классификацией ВОЗ (2008 г.) на основании гистологического, гистохимического и иммуноморфологического исследований биоптатов опухолевых тканей. Всем пациентам проводилось общеклиническое и лабораторное обследование в соответствии со стандартным планом обследования больных лимфопролиферативным заболеванием, согласно Российским клиническим рекомендациям [10, с. 9]. Оценивали жалобы, данные анамнеза, объективного обследования, клинические синдромы, результаты лабораторных и инструментальных методов исследования: 
клинический анализ крови; биохимический анализ крови (креатинин, мочевина, билирубин, общий белок, АСТ, АЛТ, ЛДГ, щелочная фосфатаза); рентгенография органов грудной клетки; УЗИ всех групп периферических лимфатических узлов с исследованием печени, селезенки; КТ шеи, органов грудной клетки, брюшной полости и таза.

Общее состояние пациента (Performance status) оценивали по шкале ECOG (0-4 балла), которая имеет следующую градацию: 0 баллов - нормальная активность; 1 балл больной способен к нормальной деятельности, хотя имеются незначительные симптомы или признаки заболевания; 2 балла - больше $50 \%$ дневного времени больной проводит не в постели, но иногда ему необходимо принять горизонтальное положение; 3 балла - больной нуждается в пребывании в постели более $50 \%$ дневного времени; 4 балла больной не способен обслуживать себя, прикован к постели [10, с. 9].

Клиническая стадия заболевания устанавливалась согласно критериям классификации Ann Arbor (1971 г.) в модификации Cotswolds (1989 г.) $[10$, c. 8$]$. Поражение одной зоны л/у или лимфатической структуры соответствует I стадии, двух и более зон л/у по одну сторону диафрагмы - II стадии, зон л/у или лимфатических структур по обе стороны диафрагмы III стадии, диссеминированное поражение одного или более экстралимфатического органа VI стадии. Поражение одного экстралимфатического органа обозначают символом Е, поражение селезенки - символом S, массивное поражение в соответствии с выше описанными критериями - символом Х. Каждую стадию разделяют на А и Б в зависимости от отсутствия или наличия общих симптомов.

Поражение при лимфомах разделяли на лимфатические (нодальные) и экстралимфатические (экстранодальные, органные). К лимфатическим относят поражения л/у и лимфатических структур - Вальдейерова кольца (небные, трубные, глоточная и язычная миндалина), селезенки, вилочковой железы, аппендикса, пейеровых бляшек. Кроме этого, выделяют другие зоны л/у, не включенные в оригинальную классификацию Ann Arbor, поскольку редко поражаются при ЛГМ: эпитрохлеарные и плечевые, подколенные, внутренние маммарные и другие мелкие группы. Но стоит отметить, что эти л/у нередко поражаются при НЛХ и могут учитываться как отдельные зоны, влияя на стадию. К экстралимфатическим относятся поражения костного мозга, центральной нервной системы, орбиты (конъюктивы, слезных желез, мягких тканей), слюнных желез, легких, плевры, желудочно-кишечного тракта, печени, почек, надпочечников, мочеточников, половых и других органов $[11 ; 12$, с. 68]. 
Статистическую обработку полученных данных выполняли с помощью компьютерной программы STATISTICA 13. Описательную статистику качественных признаков представили абсолютными и относительными частотами. Для сопоставления двух выборок по частоте встречаемости интересующего явления использовали критерий Фишера. Различия считали достоверными при $\mathrm{p} \leq 0,05$; недостоверными при $\mathrm{p}>0,05$.

\section{Результаты исследования и их обсуждение}

Заболеваемость лимфомами в PX за 2014 г. составила 5,81 случая на 100 тыс. населения, всего зарегистрирован 31 случай. Исследования в промышленно развитых странах показывают бимодальное распределение заболеваемости ЛГМ с первым пиком в 20-30 лет и вторым пиком в возрасте $>50$ лет, мужчины болеют значительно чаще, чем женщины; заболеваемость НХЛ так же выше у мужчин, чем у женщин, но установлено различие - она увеличивается с возрастом - пик заболеваемости приходится на возрастную группу $>50$ лет $[13$, с. 3 ; 14 , с. $94 ; 15$, с. 31$]$. Эпидемиологический анализ, проведенный в Республике Хакасия так же выявил достоверные различия, установлено, что для ЛГМ характерна заболеваемость лиц молодого и среднего возраста, что в диапазоне 25-44 лет (средний возраст $39,6 \pm 4,9$ ), а НХЛ чаще болеют субъекты старшей

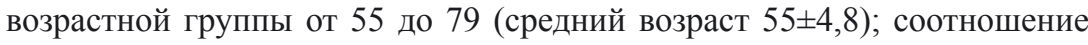
заболеваемости ЛГМ среди муж. и жен. составило $(2,3: 1)$, НХЛ $(1,4: 1)$. Анализ распределения морфологических вариантов лимфом в Хакасии за 2014 г. показал, что как при ЛГМ, так и при НХЛ преобладают не уточненные морфологические варианты, среди уточненных ЛГМ распространен нодулярный склероз $(9,67 \%)$ и лимфоидное преобладание $(6,45 \%)$, что характерно в большей мере для западного типа распределения заболеваемости, нежели чем азиатского, где в большинстве стран преобладает смешанно-клеточная форма. Особенностью является высокая частота встречаемости в Республике Хакасия этих двух морфологических форм, тогда как по данным ряда исследований, лимфоидное преобладание встречается редко, по отношению к другим формам. Среди уточненных НХЛ в Хакасии имеет наибольшее распространение диффузная неходжкинская лимфома (19,35\%), как и в большинстве стран мира. На втором месте по встречаемости идет фолликулярная неходжкинская лимфома $(9,67 \%)$, что характерно для западного типа распределения. Оценка показателей заболеваемости лимфомами среди городского и сельского населения выявила различия - у городского населения чаще встречается НХЛ, 
что составляет $82,4 \%$ (ЛГМ - 17,6\%) (p $\leq 0,05)$, у сельского же населения соотношение встречаемости НХЛ и ЛГМ одинаковое $(\mathrm{p} \leq 0,05)$ [16, с. 103].

Для проведения анализа диагностических показателей при различных клинико-морфологических вариантах лимфом определили критерии включения, в анализируемые группы вошли пациенты, проходившие стационарное лечение в ГБУЗ РХ «Республиканском онкологическом диспансере» (19 пациентов из 31 впервые выявленных в 2014 г.). У всех пациентов был определен статус по ECOG, изучены результаты лабораторных и инструментальных методов исследования (таблица 1,2 ). Локализацию поражения на момент постановки диагноза изучали по результатам следующих инструментальных методов исследования: рентгенография органов грудной клетки в двух проекциях; КТ шеи, грудной клетки, органов брюшной полости и малого таза; МРТ органов брюшной полости, малого таза; УЗИ периферических, внутрибрюшных и забрюшинных ЛУ и органов брюшной полости. Абсолютно всем пациентам с целью морфологической верификации диагноза была проведена эксцизионная биопсия наибольшего пораженного л/у, с последующим проведением гистологического (РГИ) и иммуногистохимического (ИГХ) исследования.

Таблича 1.

Характеристика клинико-лабораторных признаков в анализируемых группах

\begin{tabular}{|c|c|c|c|}
\hline Показатель & $\begin{array}{c}\text { ЛГМ } \\
\text { [абс. число (\%)] }\end{array}$ & $\begin{array}{c}\text { НХЛ (\%) } \\
\text { [абс. число (\%)] }\end{array}$ & $\begin{array}{c}\text { Критерий } \\
\text { Фишера (р) }\end{array}$ \\
\hline Количество пациентов & $4(100)$ & $15(100)$ & - \\
\hline Соотношение М/Ж & $2 / 2$ & $6 / 9$ & - \\
\hline $\begin{array}{l}\text { Возраст: } \\
-<60 \\
->60\end{array}$ & $\begin{array}{c}4 / 4(100) \\
0 / 4(0)\end{array}$ & $\begin{array}{c}4 / 15(26,6) \\
11 / 15(73,3)\end{array}$ & $\begin{array}{l}0,02 \\
0,02\end{array}$ \\
\hline $\begin{array}{l}\text { Стадия Ann - Arbor: } \\
\text { - I } \\
\text { - II } \\
\text { - III } \\
\text { - IV }\end{array}$ & $\begin{array}{l}0 / 4(0) \\
1 / 4(25) \\
2 / 4(50) \\
1 / 4(25)\end{array}$ & $\begin{array}{l}1 / 15(6,6) \\
6 / 15(40) \\
6 / 15(40) \\
2 / 15(13,3)\end{array}$ & $\begin{array}{l}0,8 \\
0,5 \\
0,6 \\
0,5\end{array}$ \\
\hline $\begin{array}{l}\text { Наличие В-симптомов: } \\
\text { - Лихорадка } \uparrow 38^{\circ} \mathrm{C} \text { не } \\
\text { менее } 3 \text { дней подряд без } \\
\text { признаков воспаления } \\
\text { - Ночные профузные поты } \\
\text { - Похудение на } 10 \% \text { мас- } \\
\text { сы тела за } 6 \text { мес. }\end{array}$ & $\begin{array}{l}1 / 4(25) \\
0 / 4(0) \\
0 / 4(0)\end{array}$ & $\begin{array}{l}1 / 15(6,6) \\
3 / 15(20) \\
1 / 15(6,6)\end{array}$ & $\begin{array}{l}0,4 \\
0,5 \\
0,8\end{array}$ \\
\hline
\end{tabular}


Окончание табл. 1.

\begin{tabular}{|c|c|c|c|}
\hline $\begin{array}{l}\text { Статус по ECOG: } \\
-0 \\
\text { - I } \\
\text { - II } \\
\text { - III } \\
\text { - IV }\end{array}$ & $\begin{array}{c}0 / 4(0) \\
3 / 4(75) \\
1 / 4(25) \\
0 / 4(0) \\
0 / 4(0)\end{array}$ & $\begin{array}{c}0 / 15(0) \\
12 / 15(80) \\
3 / 15(20) \\
0 / 15(0) \\
0 / 15(0) \\
\end{array}$ & $\begin{array}{c}- \\
0,6 \\
0,6 \\
- \\
-\end{array}$ \\
\hline \multicolumn{4}{|c|}{ Лабораторные методы исследования: } \\
\hline $\begin{array}{l}\text { Развернутый анализ } \\
\text { крови: } \\
\text { - анемия } \\
\text { - лейкоцитоз } \\
\text { - тромбоцитопения } \\
\text { - } \text { СОЭ }\end{array}$ & $\begin{array}{l}1 / 4(25) \\
1 / 4(25) \\
1 / 4(25) \\
3 / 4(75)\end{array}$ & $\begin{array}{c}7 / 15(46,6) \\
5 / 15(33,3) \\
9 / 15(60) \\
11 / 15(73,3)\end{array}$ & $\begin{array}{l}0,4 \\
0,6 \\
0,2 \\
0,7\end{array}$ \\
\hline $\begin{array}{l}\text { Биохимический анал } \\
\text { крови: } \\
\text { - } \downarrow \text { общий белок } \\
\text { - } \uparrow \text { общий билирубин } \\
\text { - } \uparrow А Л Т ~ \\
\text { - } \text { АСТ } \\
\text { - } \text { ЩФ } \\
\text { - } \uparrow \text { ЛДГ } \\
\text { - } \uparrow \text { Церрулоплазмин }\end{array}$ & $\begin{array}{c}2 / 4(50) \\
1 / 4(25) \\
2 / 4(50) \\
1 / 4(25) \\
2 / 4(50) \\
2 / 3(66,6) \\
1 / 3(33,3) \\
\end{array}$ & $\begin{array}{c}4 / 15(26,6) \\
3 / 15(20) \\
1 / 15(6,6) \\
1 / 15(6,6) \\
1 / 9(11,1) \\
5 / 6(83,3) \\
3 / 6(50) \\
\end{array}$ & $\begin{array}{r}0,4 \\
0,6 \\
0,09 \\
0,4 \\
0,2 \\
0,6 \\
0,6 \\
\end{array}$ \\
\hline
\end{tabular}

Характер клинических проявлений при лимфомах и интенсивность выраженности отдельных симптомов зависит главным образом от степени дифференцировки клеток, составляющих морфологический субстрат опухоли. Первые клинические проявления лимфомы могут быть различными. Однако чаще дебют заболевания развивается по одному из 3 сценариев: 1. Увеличение одного или нескольких лимфатических узлов с более или менее быстрым ростом. 2. Наличие экстранодальной опухоли с характерными проявлениями (например, кожные лимфомы, лимфома желудочно-кишечного тракта или др.). 3. Системная манифестация в виде лихорадки, потери массы тела, слабости $[17$, с. 6].

Сравнительный анализ непараметрических данных (анализируемых признаков) с использованием точного критерия Фишера показал, что в группах больных с ЛГМ и НХЛ имеются достоверно значимые различия по следующим показателям: возрастной критерий - для ЛГМ характерен возраст $<60$ лет, для НХЛ $>60$ лет $(\mathrm{p} \leq 0,05)$. Для остальных показателей (стадия по Ann - Arbor, наличие B-симптомов, статус по ECOG, лабораторные методы исследования (показатели развернутого анализа крови - анемия,

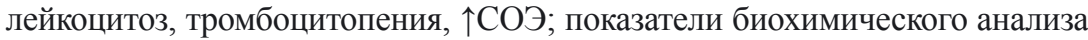


крови рулоплазмин) достоверно значимых различий получено не было (p>0,05).

Таблица 2.

Характеристика зон поражения в анализируемых группах

\begin{tabular}{|c|c|c|c|}
\hline Показатель & $\begin{array}{c}\text { ЛГМ } \\
\text { [абс. число } \\
\text { (\%)] }\end{array}$ & $\begin{array}{c}\text { НХЛ (\%) } \\
\text { [абс. число } \\
\text { (\%)] }\end{array}$ & $\begin{array}{c}\text { Критерий } \\
\text { Фишера (p) }\end{array}$ \\
\hline \multicolumn{4}{|c|}{ Локализация поражения на момент постановки диагноза: } \\
\hline Изолированная лимфаденопатия & $0 / 4(0)$ & $3 / 15(20)$ & 0,5 \\
\hline $\begin{array}{l}\text { Изолированные экстранодальные } \\
\text { поражения }\end{array}$ & $0 / 4(0)$ & $3 / 15(20)$ & 0,5 \\
\hline Генерализованное поражение & $4 / 4(100)$ & $9 / 15(60)$ & 0,2 \\
\hline \multicolumn{4}{|c|}{ Характерные зоны поражения: } \\
\hline Вальдейерово кольцо & $0 / 4(0)$ & $3 / 15(20)$ & 0,5 \\
\hline Заушные л/у & $0 / 4(0)$ & $1 / 15(6,6)$ & 0,8 \\
\hline Шейные л/у & 4/4 (100) & $9 / 15(60)$ & 0,2 \\
\hline Подчелюстные л/у & $0 / 4(0)$ & $4 / 15(26,6)$ & 0,3 \\
\hline Аксилярные л/у & $0 / 4(0)$ & $5 / 15(33,3)$ & 0,3 \\
\hline Надключичные л/у & $3 / 4(75)$ & $5 / 15(33,3)$ & 0,2 \\
\hline Подключичные л/у & $2 / 4(50)$ & $4 / 15(26,6)$ & 0,4 \\
\hline Подмышечные л/у & $4 / 4(100)$ & $6 / 15(40)$ & 0,05 \\
\hline Л/у средостения & $2 / 4(50)$ & $10 / 15(66,6)$ & 0,5 \\
\hline Л/у ворот печени & $2 / 4(50)$ & $0 / 15(0)$ & $\mathbf{0 , 0 3}$ \\
\hline Парааортальные л/у & $2 / 4(50)$ & $2 / 15(13,3)$ & 0,2 \\
\hline Паракавальные л/у & $2 / 4(50)$ & $0 / 15(0)$ & $\mathbf{0 , 0 3}$ \\
\hline Чревные л/у (верхне-абдоминальные) & $2 / 4(50)$ & $0 / 15(0)$ & $\mathbf{0 , 0 3}$ \\
\hline $\begin{array}{l}\text { Паравертебральные л/у } \\
\text { (нижне-абдоминальные) }\end{array}$ & $2 / 4(50)$ & $0 / 15(0)$ & 0,03 \\
\hline Забрюшинные л/у & $1 / 4(25)$ & $4 / 15(26,6)$ & 0,7 \\
\hline Подвздошные л/у & $2 / 4(50)$ & $0 / 15(0)$ & $\mathbf{0 , 0 3}$ \\
\hline Паховые л/y & $3 / 4(75)$ & $3 / 15(20)$ & 0,07 \\
\hline Бедренные л/у & $1 / 4(25)$ & $0 / 15(0)$ & 0,2 \\
\hline $\begin{array}{l}\text { Экстранодальные поражения: } \\
\text { - мягкие ткани } \\
\text { - кости } \\
\text { - легкие } \\
\text { - печень } \\
\text { - толстая кишка } \\
\text { - яички } \\
\end{array}$ & $\begin{array}{l}0 / 4(0) \\
1 / 4(25) \\
1 / 4(25) \\
0 / 4(0) \\
0 / 4(0) \\
0 / 4(0) \\
\end{array}$ & $\begin{array}{l}2 / 15(13,3) \\
0 / 15(0) \\
1 / 15(6,6) \\
1 / 15(6,6) \\
1 / 15(6,6) \\
1 / 15(6,6) \\
\end{array}$ & $\begin{array}{l}0,6 \\
0,2 \\
0,4 \\
0,7 \\
0,7 \\
0,7\end{array}$ \\
\hline $\begin{array}{l}\text { Вовлечение > } 1 \text { экстранодальной } \\
\text { зоны }\end{array}$ & $0 / 4(0)$ & $0 / 15(0)$ & - \\
\hline
\end{tabular}


Клиническое течение ЛГМ зависит от локализации первичного очага, степени вовлечения в процесс близлежащих органов и морфологического варианта заболевания, чаще начинается с увеличения одного или нескольких л/у шейно-надключичной, подмышечной или паховой области. Поражение л/у выше диафрагмы встречается почти в 90\% случаев и только у 10\% больных изменения наблюдаются в поддиафрагмальных лимфатических коллекторах. Заболевание чаще всего начинается с увеличения узлов шеи - в 50-75\% всех случаев. Поражение л/у надключичных наблюдается в $25 \%$ случаев; подмышечной области в $13 \%$; средостения $10-20 \%$; забрюшинных встречается редко $(0,6-7,5 \%)$; пахово-бедренных (3-5\%). Вовлечение селезенки в процесс происходит в 65-86\% случаев; легких в $20-40 \%$; костей $15-30 \%$; печени выявляется в 5-10\% при первичной диагностике, по данным аутопсии - в 30-80\%; костного мозга диагностируются в 2-5\%, на аутопсии опухоль выявляется в 20-29\% [18, с. 15-18]. Полученные нами данные (таблица 2) в целом соответствуют литературным: у всех впервые выявленных пациентов с ЛГМ диагностировано генерализованное поражение $(100 \%)$ с характерными зонами шейные и подмышечные л/у в 100\% случаев; надключичных и паховых л/у в 75\%; из экстранодальных поражений выявлено поражение костей и легких в $25 \%$ случаев.

НХЛ начинаются так же с появления одиночного опухолевого узла и распространяются путем лимфогенного и гематогенного метастазирования. Первичный опухолевый очаг может локализоваться в л/у (нодальное поражение) или в других органах и тканях (экстранодальное поражение). Клинические проявления определяются расположением опухолевых очагов. Отмечается отчетливая разница в частоте поражения разных органов и тканей: так, поражение медиастинальных л/у возникает реже, чем при ЛГМ, составляя 15-25\%, паренхиматозные легочные поражения встречается в 3-6\% случаев, вовлечение в процесс селезенки составляет $30-40 \%$, печени $-15-50 \%$, костей $-5-15 \%$, желудочно-кишечного тракта -10 $24 \%$, костного мозга - 30-40\%. Наиболее часто первыми проявлениями болезни бывает поражение л/у (45-50\%); при этом периферические л/у вовлекаются в процесс значительно чаще (35-38\%), чем медиастинальные, забрюшинные и внутрибрюшные. Экстранодальные очаги часто возникают в ЖКТ, лимфоидном кольце Пирогова-Вальдейера, коже, ЦНС, реже - в плевре, легких, костях, мягких тканях и т.д. [19; 20, с. 176]. По результатам нашего исследования в 60\% диагностировано генерализованное поражение; выявлены наиболее часто поражающиеся зоны 
л/у: средостения в $66,6 \%$ случаев; шейные в 60\%; подмышечные в $40 \%$; аксилярные и надключичные в 33,3\%; подчелюстные, подключичные и забрюшинные в $26,6 \%$. Из экстранодальных поражений наиболее часто встречающееся поражение мягких тканей, выявленное в 13,3\% случаев. В целом полученные данные (таблица 2) соответствуют литературным источникам.

Сравнительный анализ непараметрических данных (анализируемых признаков) с использованием точного критерия Фишера показал, что в группах больных с ЛГМ и НХЛ имеются достоверно значимые различия по следующим показателям: характерные зоны поражения - при ЛГМ чаще поражаются следующие группы л/у: подмышечные, ворот печени, паракавальные, чревные (верхне-абдоминальные), паравертебральные (нижне-абдоминальные), и подвздошные ( $\mathrm{p} \leq 0,05)$. Для остальных показателей: локализация поражения на момент постановки диагноза; наличие экстранодальных зон поражения), а также следующих характерных групп поражения л/у - Вальдейерово кольцо, заушные, шейные, подчелюстные, аксилярные, надключичные, подключичные, средостения, парааортальные, забрюшинные, паховые, бедренные - достоверно значимых различий получено не было (p>0,05).

\section{Заключение}

Изучение эпидемиологических особенностей первичной заболеваемости лимфомами в Республике Хакасия за 2014 г. выявило следующее: чаще встречаются неходжкинские лимфомы (НХЛ); заболеваемость лиц мужского пола выше, чем женского; среди уточненных морфологических вариантов ЛГМ распространен нодулярный склероз и лимфоидное преобладание, среди НХЛ имеет наибольшее распространение диффузная неходжкинская лимфома; отмечено, что НХЛ чаще встречается у городского население. Сравнительный анализ непараметрических данных (анализируемых диагностических признаков), характерных для ЛГМ и НХЛ с использованием критерия Фишера установил достоверно значимые различия по следующим показателям: возрастной критерий - для ЛГМ характерен возраст < 60 лет, для НХЛ > 60 лет; характерные зоны поражения - при ЛГМ чаще поражаются следующие группы л/у: подмышечные, ворот печени, паракавальные, чревные (верхне-абдоминальные), паравертебральные (нижне-абдоминальные), и подвздошные.

Область применения результатов. Организация здравоохранения, онкология, внутренние болезни. 


\section{Список литературы}

1. Stedman T.L. Stedman`s Medical Dictionary. 28th Edition. Lippincott Williams \& Wilkins. 2005. 2100 p. ISBN: 0-7817-3390-1.

2. Джалинов А.Ф. Неходжкинские лимфомы: основы классификации и иммуноцитохимической диагностики // Онкология. Т.15. №4. 2013. С. 264-272.

3. Эпидемиологический аспекты онкогематологических заболеваний в регионе Сибири и Дальнего Востока в 1989-1998 гг. / Писарева Л.Ф., Недавняя И.О., Чойнзонов Е.Л., Тахауов Р.М., Бояркина А.П., Одинцова И.Н., Мартынова Н.А., Буторин И.Ю., Карпов А.Б., Гольдин В.Д. // Сибирский онкологический журнал. 2002. №4. С. 133-137.

4. Swerdlow A.J. Epidemiology of hodgkin's disease and non-Hodgkin's lymphoma. European Journal of Nuclear Medicine and Molecular Imaging, 2003, Vol. 30, pp. 3-12.

5. Cartwright R., Brincker H., Carli P.M. Et al. The rise in incidence of lymphomas in Europe 1985-1992. Eur. J. Cancer, 1999, Vol. 35, no. 4, pp. 627-633.

6. Zhang X., Condon J.R., Rumbold A.R., Cunningham J., Roder D.M. Estimating cancer incidence in Indigenous Australians. Aust N Z J Public Health, 2011, Vol. 35, no. 5, pp. 477-485.

7. Криволапов Ю.А. Результаты гистологического и иммуногистохимического исследования первичных биопсий у 400 больных неходжкинскими лимфомами в Северо-Западном регионе России (в соответствии с классификацией ВОЗ) // Терапевтический архив. 2004. № 7. С. 54-62.

8. Каприна А.Д., Старинского В.В., Петрова Г.В. Злокачественные новообразования в России в 2013 году (заболеваемость и смертность). М.: МНИОИ им. П.А. Герцена филиал ФГБУ «ФМИЦ им. П.А. Герцена» Минздрава России. 2015. 250 с.

9. Войцеховский В.В. Осипова Е.А. Анализ заболеваемости гемобластозами в Амурской области // Актуальные вопросы диагностики и лечения внутренних болезней. Благовещенск. 2004. С. 138-140.

10. Российские клинические рекомендации по диагностике и лечению лимфопролиферативных заболеваний / Л.С. Аль-Ради, И.Э. Белоусова, Е.А Барях, С.С. Бессмельцев, О.М. Вотякова и др. // Под руководством профессора И.В. Поддубной, профессора В.Г. Савченко М.: Медиа Медика. 2013. 104 с.

11. Armitage, J.O. Stating Non-Hodgkin Lymphoma. Cancer J.Clin, 2005, Vol. 55. N6, pp. 368-376.

12. Хоружик С.А., Жаврид Э.А., Сачивко Н.В. Система стадирования лимфом: исторические аспекты и современное стояние // Онкологический журнал. Т8. №3(31). 2014. С. 66-72. 
13. Pareen S., Alison M., Neha M., Christopher R. Incidence patterns and outcomes for Hodgkin lymphoma patients in the United States. Advances in Hematology. 2011. Article ID: 725219,10 p. http://dx.doi.org/10.1155/2011/725219.

14. Смирнова О.В., Штыгашева О.В. Болезни органов кроветворения. Абакан: Издательство ФГБОУ ВПО «Хакасский государственный университет им. Н. Ф. Катанова», 2015. 160 с.

15. Гончарова О.В., Липатов О.Н. Анализ клинико-морфологических вариантов неходжкинских лимфом // Сибирский онкологический журнал. 2009. №5. С. 30-36.

16. Смирнова О.В., Штыгашева О.В., Каблуков В.С. Анализ заболеваемости лимфомами в Республике Хакасия за 2014 год и её эпидемиологические особенности // В мире научных открытий. 2016. №4(76). С. 98-111.

17. Угляница К.Н. Злокачественные лимфомы // Журнал ГГМУ. №2. 2003. C. $3-10$.

18. Крутилина Н.И. Лимфома Ходжкина: методические рекомендации. Мн.: БелМАПО. 2008. 31 с.

19. Давыдов М.И., Ганцев Ш.Х. Онкология: учеб. ГЭОТАР-Медиа, 2010. 920 с.

20. Поддубная И.В., Дёмина Е.А. Диагностика и определение распространенности (стадирования) неходжкинских лимфом // Практическая онкология. T.5. №3. 2004. C. 176-184.

\section{References}

1. Stedman, T.L. Stedman`s Medical Dictionary. 28th Edition. Lippincott Williams \& Wilkins. 2005. 2100 p. ISBN: 0-7817-3390-1.

2. Dzhalinov A.F. Nehodzhkinskie limfomy: osnovy klassifikacii i immunocitohimicheskoj diagnostiki [Non-Hodgkin's lymphoma: principles of classification, and immunocytochemical diagnosis]. Onkologija [Cancer.]. T.15. №4. 2013, pp. 264-272.

3. Pisareva L.F., Nedavnyaya I.O., Choynzonov E.L., Takhauov R.M., Boyarkina A.P., Odintsova I.N., Martynova N.A., Butorin I.Yu., Karpov A.B., Goldin V.D. Epidemiologicheskiy aspekty onkogematologicheskikh zabolevaniy v regione Sibiri i Dal'nego Vostoka v 1989-1998 [Epidemiological aspects of oncohematological diseases in the region of Siberia and the Far East in 1989 and 1998]. Sibirskiy onkologicheskiy zhurnal [Siberian journal of cancer]. 2002, no.4, pp. 133-137.

4. Swerdlow A.J. Epidemiology of Hodgkin's disease and non-Hodgkin's lymphoma. European Journal of Nuclear Medicine and Molecular Imaging, 2003, Vol. 30, pp. 3-12.

5. Cartwright R., Brincker H., Carli P.M. Et al. The rise in incidence of lymphomas in Europe 1985-1992. Eur. J. Cancer, 1999, Vol. 35, no. 4, pp. 627-633. 
6. Zhang X., Condon J.R., Rumbold A.R., Cunningham J., Roder D.M. Estimating cancer incidence in Indigenous Australians. Aust N Z J Public Health, 2011, Vol. 35, no. 5, pp. 477-485.

7. Krivolapov Yu.A. Rezul'taty gistologicheskogo i immunogistokhimicheskogo issledovaniya pervichnykh biopsiy u 400 bol'nykh nekhodzhkinskimi limfomami v Severo-Zapadnom regione Rossii (v sootvetstvii s klassifikatsiey VOZ) [The results of histological and immunohistochemical studies of primary biopsies from 400 patients with non-Hodgkin lymphomas in North-West region of Russia (in accordance with the who classification)]. Terapevticheskiy arkhiv [Therapeutic archive], 2004, no. 7, pp. 54-62.

8. Kaprin A.D., Starinskiy V.V., Petrov G.V. Zlokachestvennye novoobrazovaniya v Rossii v 2013 godu (zabolevaemost' i smertnost') [Malignant neoplasms in Russia in 2013 (morbidity and mortality)]. Moscow: Moscow Scientific research oncological Institute named after P. A. Gertsen, 2015. 250 p.

9. Voytsekhovskiy V.V. Osipova E.A. Analiz zabolevaemosti gemoblastozami v Amurskoy oblasti [Analysis of the incidence of hematological malignancies in the Amur region]. Aktual'nye voprosy diagnostiki i lecheniya vnutrennikh bolezney [Topical issues of diagnosis and treatment of internal diseases]. Blagoveschensk, 2004, pp. 138-140.

10. Al'-Radi L.S., Belousova I.Je., Barjah E.A., Bessmel'cev S.S., Votjakova O.M. et al. Roscijskie klinicheskie rekomendacii po diagnostike i lecheniju limfoproliferativnyh zabolevanij [Russian clinical recommendations on diagnostics and treatment of lymphoproliferative disorders] / I.V. Poddubnaya, V.G. Savchenko M.: Media Medika. 2013. 104 p.

11. Armitage J.O. Stating Non-Hodgkin Lymphoma. Cancer J.Clin, 2005, Vol. 55. N6, pp. 368-376.

12. Horuzhik S.A., Zhavrid Je.A., Sachivko N.V. Sistema stadirovanija limfom: istoricheskie aspekty i sovremennoe stojanie [The system of staging of lymphomas: historical aspects and current state]. Onkologicheskij zhurnal [journal of Oncology]. T8. №3(31). 2014, pp. 66-72.

13. Pareen S., Alison M., Neha M., Christopher R. Incidence patterns and outcomes for Hodgkin lymphoma patients in the United States. Advances in Hematology, 2011. Article ID: 725219,10 p. http://dx.doi.org/10.1155/2011/725219.

14. Smirnova O.V., Shtygasheva O.V. Bolezni organov krovetvoreniya [Diseases of the blood]. Abakan: Khakas State University of N.F. Katanov, 2015. $160 \mathrm{p}$.

15. Goncharova O.V., Lipatov O.N. Analiz kliniko-morfologicheskikh variantov nekhodzhkinskikh limfom [Analysis of clinical and morphological variants of 
non-Hodgkin's lymphomas]. Sibirskiy onkologicheskiy zhurnal [Siberian journal of cancer], 2009, no. 5, pp. 30-36.

16. Smirnova O.V., Shtygasheva O.V., Kablukov V.S. Analiz zabolevaemosti limfomami v Respublike Hakasija za 2014 god i ejo jepidemiologicheskie osobennosti [Analysis of the incidence of lymphomas in the Republic of Khakassia in 2014 and its epidemiological characteristics]. V mire nauchnyh otkrytij [In the world of scientific discoveries]. 2016. №4(76), pp. 98-111.

17. Ugljanica K.N. Zlokachestvennye limfomy [Malignant lymphoma]. Zhurnal GGMU [GSMU]. №2. 2003, pp. 3-10.

18. Krutilina N.I. Limfoma Hodzhkina: metodicheskie rekomendacii [Hodgkin's lymphoma: guidelines]. Mn.: BelMAPO. 2008. 31 p.

19. Davydov M.I., Gancev Sh.H. Onkologija [Ghanaians Oncology]: textbook. GEOTAR-Media, 2010. $920 \mathrm{p}$.

20. Poddubnaja I.V., Djomina E.A. Diagnostika i opredelenie rasprostranennosti (stadirovanija) nehodzhkinskih limfom [Diagnosis and identifying the extent (staging) of non-Hodgkin lymphoma]. Prakticheskaja onkologija [Practical Oncology]. V.5. №3. 2004, pp. 176-184.

\section{ДАННЫЕ ОБ АВТОРАХ}

Смирнова Ольга Валентиновна, д.м.н., профессор, заведующая лабораторией клинической патофизиологии

Федеральное государственное бюджетное научное учреждение "Федеральный исследовательский иентр «Красноярский научный иентр Сибирского отделения Российской академии наук» «Научно-исследовательский институт медицинских проблем Севера»; Федеральное государственное бюджетное образовательное учреждение выстего образования «Хакасский государственный университет им. Н.Ф. Катанова»

ул. Партизана Железняка, 32, г. Красноярск, 660022, Российская Федеращия; ул. Ленина, 90, г. Абакан, Республика Хакасия, 655000, Российская Федерачия ovsmirnova71@mail.ru

Штыгашева Ольга Владимировна, д.м.н., профессор, зав. кафедрой внутренних болезней медико-психолого-социального института Федеральное государственное бюджетное образовательное учреждение выстего образования «Хакасский государственный университет им. Н.Ф. Катанова» 
ул. Ленина, 90, г. Абакан, Республика Хакасия, 655000, Российская Федераиия

olgashtygasheva@rambler.ru

Каблуков Виталий Сергеевич, клинический ординатор кафедры внутренних болезней Федеральное государственное бюджетное образовательное учреждение выстего образования «Хакасский государственный университет им. Н.Ф. Катанова» ул. Ленина, 90, г. Абакан, Республика Хакасия, 655000, Российская Федерачия vitala600@yandex.ru ORCID: 0000-0002-2765-6726 SPIN-код: 3261-5064

\section{DATA ABOUT THE AUTHORS}

Smirnova Olga Valentinovna, MD, Professor, Head of the Laboratory of Clinical Pathophysiology

Scientific Research Institute of Medical Problems of the North; Katanov Khakass State University

3g, Partizan Zheleznyaka Str., Krasnoyarsk, 660022, Russian Federation; 90, Lenin Str., Abakan, Republic of Khakassia, 655000, Russian Federation ovsmirnova71@mail.ru

Shtygasheva Olga Vladimirovna, MD, Professor, Head of the Department of Internal Medicine

Katanov Khakass State University

90, Lenin Str., Abakan, Republic of Khakassia, 655000, Russian Federation

olgashtygasheva@rambler.ru

Kablukov Vitaly Sergeevich, clinical intern of the Department of Internal Medicine

Katanov Khakass State University

90, Lenin Str., Abakan, Republic of Khakassia, 655000, Russian Federation

vitala600@yandex.ru

ORCID: 0000-0002-2765-6726

SPIN-code: 3261-5064 